\title{
High power factor operation of resonant converters on the utility line
}

\author{
A K S BHAT and V BELAGULI* \\ Department of Electrical and Computer Engineering, University of Victoria, \\ Victoria (BC), V8W 3P6, Canada \\ Present address: Department of Electrical Engineering, Singapore Polytechnic, \\ Singapore 139651 \\ e-mail: bhat@ece.UVic.CA; belaguli@sp.ac.sg
}

\begin{abstract}
Operation and characteristics of resonant converters on the utility line are presented. Series-parallel (LCC-type) resonant converter operating with discontinuous current mode and continuous current mode (variable frequency control as well as fixed-frequency) are considered. Design examples are presented. SPICE simulation and experimental results obtained for the designed converters (rated at $150 \mathrm{~W}$ ) are presented to verify the theory. It is shown that high line power factor $(>0.95)$ and line current total harmonic distortion (THD) of $<25 \%$ are obtained for the LCC-type converter for a wide load range (from full load to $10 \%$ rated load) without any active control, and the switch peak current decreases with the load current. With active line current control, low distortion and zero voltage switching for the entire cycle are realized.
\end{abstract}

Keywords. Resonant converters; power factor; zero-voltage-switching; zerocurrent-switching.

\section{Introduction}

During the last few years, high-frequency (HF) soft-switching (including resonant) converters have gained popularity due to their advantages compared to hard-switching PWM converters. Some of the advantages are: zero-voltage-switching (ZVS) or zero-currentswitching (ZCS) reducing switching losses, high efficiency, higher switching frequency, small size, low weight etc. The ZVS or ZCS reduces the switch stresses during the switch turn-on or turn-off instants. Many of the configurations utilize the leakage inductance of the HF transformer as part of the resonant inductor eliminating the voltage spike problems present in PWM converters.

With an increase in the number of power converters operating on the utility line, harmonics generated by these converters have become a matter of great concern. Due to the enforcement (either already existing or being proposed) of strict harmonic regulations 
(e.g. IEC555), there is an increased interest in the reduction or elimination of line current harmonics. The methods proposed or implemented in the literature to reduce the line current harmonics can be classified as:

(1) use of line filters (active or passive);

(2) use of power converters with active control of line current (Kataoka et al 1979; Kocher \& Steigerwald 1983; He \& Mohan 1987);

(3) modifications to the existing converters (Schlecht \& Miwa 1987; Keraluwala et al 1991; Schutten et al 1991). The last method is the simplest solution.

Advantages of HF resonant converters can be utilized in $a c$-to- $d c$ converters (Chambers 1983; Nijhof 1986; He \& Mohan 1987; Schlecht \& Miwa 1987; Keraluwala et al 1991; Schutten et al 1991; Belaguli \& Bhat 1995; Belaguli 1996) for realizing power conversion with improved performance (high efficiency, high power factor and low line current harmonics etc.) while reducing the size, weight and cost. Perhaps the earliest work in this area was reported by Chambers (1983). The series resonant converter (SRC) operating in discontinuous current mode (DCM) was used without any line current control. Due to forced shut off of the SRC when the line voltage is around $50 \%$ of its peak value, the maximum power factor achievable and reduction in total harmonic distortion (THD) are limited. Active line current wave shaping has been used in a single ended resonant converter ( He \& Mohan 1987).

\section{Resonant converters and their operation on the utility line}

A number of resonant converter configurations are realizable using different resonant tank circuits (Steigerwald 1988; Bhat 1991) and the three most popular configurations are: series resonant (or series loaded) converter (SRC), parallel resonant (or parallel loaded) converter (PRC) and series-parallel (or LCC-type) resonant converter (SPRC). Load voltage regulation in such converters for input supply variations and load changes is achieved by either varying the switching frequency or using fixed-frequency (variable pulse-width) control. The SRC has high efficiency from full load to part load. But it requires wide variation in switching frequency for power control and the output filter capacitor must carry high ripple current when used in low output voltage and large load current application. The PRC is suitable for low output voltage with large load current applications and it requires narrow variation in switching frequency for power control. However, peak currents through the switches do not decrease with load current reducing the efficiency at reduced loads. The SPRC takes the desirable features of both SRC and the PRC.

Keraluwala et al (1991), Schutten et al (1991) and Belaguli \& Bhat (1995) have reported the operation of resonant converters with high power factor. But the line current harmonic distortion was very high ( $18 \%$ minimum around half-load to about $48 \%$ at full-load) and the switch peak current did not decrease with the load current since PRC was used (Schutten et al 1991). Use of LCC-type converter had been discussed briefly. The major problem was the requirement of keeping the ratio of switching frequency to series resonance frequency high in order to maintain lagging $p f$ (above resonance) mode of operation, resulting in higher switch peak currents. 
Conventionally, HF link $d c$-to- $d c$ resonant converters were operated with a smooth $d c$ input. This means, when the converter has to be operated on the utility line, a line rectifier followed by a large filter capacitor $\left(C_{i}\right)$ has to be used to get a $d c$ supply. The disadvantages of this approach are well known: High peak currents drawn from the line with a total harmonic distortion (THD) greater than $80 \%$ and low line $p f(<0.65)$. However, in an ideal single-phase $a c$-to- $d c$ converter, the input line current has to be sinusoidal and in phase with the line voltage. This results in power with a double line frequency $\left(2 f_{L}\right.$, where $f_{L}$ is the line frequency) having a peak value of $2 P_{o}$, where $P_{o}$ is the average output power.

In the proposed $a c$-to- $d c$ converters, a small $\mathrm{HF}$ filter capacitor $C_{i}$ is used at the input (Schutten et al 1991; Belaguli \& Bhat 1995; Belaguli 1996). The $d c$ link voltage in this case is approximately a rectified sine wave. This allows the HF inverter to draw current from the utility line over the entire cycle reducing the peak currents. However, a large capacitive output filter $C_{d}$ is required to filter the $120 \mathrm{~Hz}$ voltage ripple at the output to obtain a constant voltage $V_{o}$. Due to the rectified sine-wave at the input of the HF inverter, the inverter output voltage $v_{a b}$ is varying and the instantaneous normalized converter gain $M(t)=V_{o}^{\prime} / v_{s}(t)$ must also vary in order to draw sinusoidal line current and maintain a constant $d c$ output voltage. The voltage gain $M(t)$ is minimum at the peak of the $a c$ voltage, and maximum near the zero crossings of the $a c$ voltage.

How closely the converter gain matches the required gain variation in order to get a line current which follows the input sine wave depends on the resonant converter configuration. In the case of SRC, the converter does not have enough gain for most part of the line cycle, thus resulting in poor $p f$ and large line current distortion. It is well known that PRC has high gain near valley points of line voltage at full load (for switching frequencies near resonance) due to its high $Q$ (for the PRC, $Q=R_{L} /\left(L_{r} / C_{p}\right)^{1 / 2}$, where $L_{r}$ and $C_{p}$ are the resonant inductance and capacitance, respectively) near zero crossings. This is because, loading varies along the $a c$ cycle, with maximum loading at the peak of $a c$ and light loading near zero crossings of $a c$ cycle. In fact, the gain obtained is much higher than required causing the line current to approach a square-wave resulting in a higher THD of line current at full load. In addition, the switch peak currents are high in the case of PRC and does not decrease with the load current. Only limited discussion on the use of LCC-type converter was given (Schutten et al 1991) due to insufficient gain available at the valley points of line voltage, and the ratio of switching frequency to series resonance frequency was kept high $(\simeq 1.51)$ to maintain lagging $p f$ (above resonance) mode of operation resulting in higher switch peak currents. But our research has shown that LCC-type converters can be operated with high $p f$ and low harmonic distortion while maintaining its advantages. Therefore, an LCC-type converter is taken as the example in this paper.

\section{Operation of SPRC on the utility line}

\subsection{Emulation of a resistor}

Figure 1 shows the SPRC (or LCC-type resonant converter) operating on the utility line. Since, $C_{i}$ is a small HF filter capacitor, as discussed earlier, input voltage to the HF inverter 


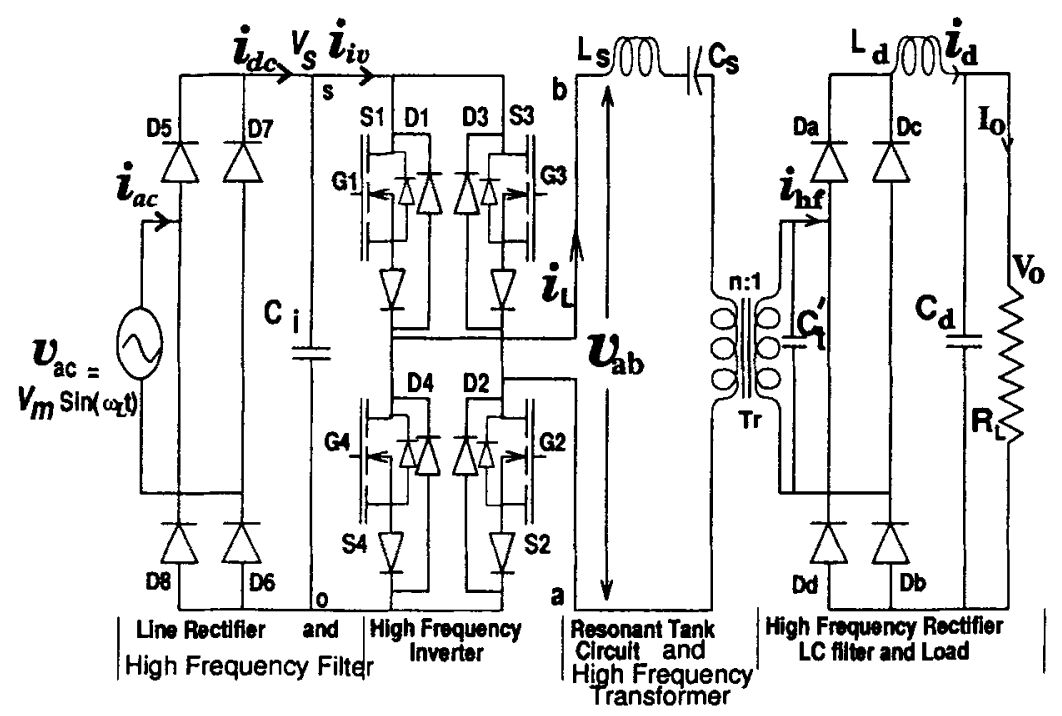

Figure 1. High-frequency transformer isolated $a c$-to- $d c$ converter employing seriesparallel resonant converter. Note that $C_{i}$ is an HF filter capacitor.

is a rectified sine-wave. The output $d c$ link filter inductor current is given by

$$
i_{d}^{\prime}(t)=I_{d m}^{\prime} \sin ^{2}\left(w_{L} t\right)
$$

where

$$
I_{d m}^{\prime}=2 P_{o} / V_{o}^{\prime}, V_{o}^{\prime}=n V_{o}
$$

Also, series resonant $Q_{s}(t)$ expressed in terms of time varying reflected load resistance achieves its maximum at the peak of the line voltage cycle, and is given by

$$
Q_{s}(t)=w_{s} L / R_{L}^{\prime}(t)=Q_{s} \max \sin ^{2}\left(w_{L} t\right)
$$

where

$$
Q_{s \max }=\left(L / C_{s}\right)^{1 / 2} / R_{L p}^{\prime}=\left(L / C_{s}\right)^{1 / 2}\left(I_{d m}^{\prime} / V_{o}^{\prime}\right),
$$

$R_{L p}^{\prime}=V_{o}^{\prime 2} /\left(2 P_{o}\right), M=V_{o}^{\prime} / V_{m}, L=L_{s}+L_{l}, L_{s}$ is the external resonant inductance, $L_{l}$ is the leakage inductance of the $\mathrm{HF}$ transformer.

Also, define: $y_{s}=2 \pi f_{s} / \omega_{s r}, \omega_{s r}=1 /\left(L C_{s}\right)^{1 / 2}, f_{s}$ is the switching frequency.

To get a sinusoidal line current, that is, for resistive emulation, the converter gain has to be changed by exercising active control. However, it is shown in later sections that, by matching the converter operating characteristics using the design constraints $(\S 3.3)$, the SPRC can be operated on the utility line, to obtain high $p f$ with low harmonic current distortion even without active control.

\subsection{Operating modes of a SPRC}

When variable frequency operation is used, depending on the switching frequency, SPRC can operate in discontinuous current mode (DCM) or continuous current mode (CCM). When fixed-frequency control is used, SPRC operates always in the CCM. 


\subsection{Design constraints}

The following are the design criteria to operate the resonant converters on the utility line with high $p f$ and low line current harmonic distortion.

(1) $Q_{s \max }$ should be chosen to minimize the inductor rms current and also the $\mathrm{kVA} / \mathrm{kW}$ rating of the resonant tank circuit. Higher $Q_{s}$ max minimizes inductor rms current, but increases its size.

(2) Depending on the type of control used for regulating the $d c$ output voltage from full load to reduced load, the range of variation in (a) switching frequency required in case of variable frequency DCM or CCM operation, or (b) phase shift (pulse width) required in case of fixed-frequency CCM operation, must be minimized while choosing the $C_{s} / C_{t}$ ratio to account for variation in input voltage in addition to the required gain $M$.

(3) The switching frequency (or pulse width) should be chosen such that the resonant converter operates only in the modes for which it is designed for full load near the peak of the supply voltage.

(4) The resonant converter generates the required gain at least from $30^{\circ}$ to $150^{\circ}$ (as most of the total output power is delivered in this range) even without active control over the $60 \mathrm{~Hz}$ (or $50 \mathrm{~Hz}$ ) $a c$ half cycle, to get lower line current distortion.

\subsection{Discontinuous current mode operation}

The converter is designed to operate in just continuous current mode (JCCM) (figure 2a) near the rated minimum peak of $a c$ line voltage with rated maximum load current and the operation will be in DCM (figure $2 b$ ) for the rest of line cycle. The output voltage is regulated by decreasing the switching frequency such that the converter operates in DCM.

In figure $2 \mathrm{a}$ when $\mathrm{S} 1$ and $\mathrm{S} 2$ are turned on, resonant current $j_{L}$ (normalized $i_{L}$ ) starts flowing with positive polarity of the voltage $v_{a b}$ applied to the tank circuit. During interval$\mathrm{C} 1, m_{c t}$ (normalized $v_{c t}$ ) $=0$ and the load is supplied by the resonant current until $j_{L}(t)=J(t)$ (normalized load current assumed to be constant over one switching half cycle) to enter interval-A. In interval-A, the resonant current in excess of instantaneous load current $J(t)$ charges the parallel capacitor $C_{t}$. The gating pulse to the switch is removed, once the diodes D1 and D2 start conducting the resonant current in interval-A due to reversal in current polarity. The diodes D1 and D2 turn off with zero current at the end of interval-C2. During the additional interval-E (dead gap) shown in figure $2 b$, the input supply to the tank circuit is cut off as all the switches are in the OFF state. It must be noted that the series capacitor voltage remains constant during interval-E (same as the voltage at the end of interval-C2), until the other pair of switches S3 and S4 are turned $\mathrm{ON}$. The duration of interval-E increases with decrease in load current. The operation of converter is similar for the other half cycle, where switches $\mathrm{S} 3$ and $\mathrm{S} 4$ are turned $\mathrm{ON}$, except for change in polarity in voltages and currents. Note that, all the high frequency rectifier diodes in the output section are in conduction during intervals- $\mathrm{C} 1$ and $\mathrm{C} 2$.

In the output section, the filter components $L_{d}$ and $C_{d}$ carry approximately $120 \mathrm{~Hz}$ current and voltage ripple respectively, under high power factor operation. The filter inductor 

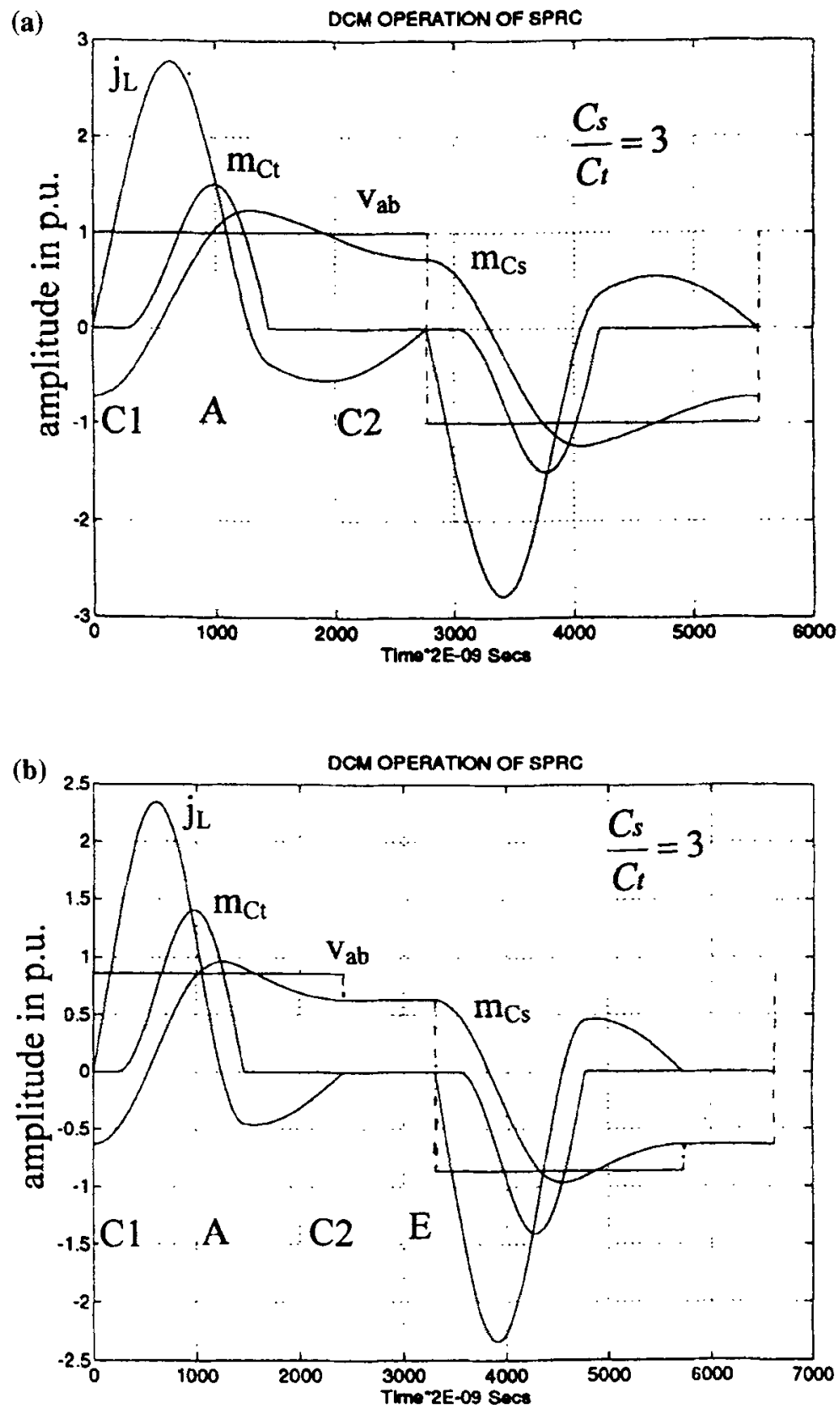

Figure 2. Normalized steady-state operating waveforms obtained from PROMATLAB for SPRC operation in DCM. (a) Just CCM operation. (b) DCM operation. 

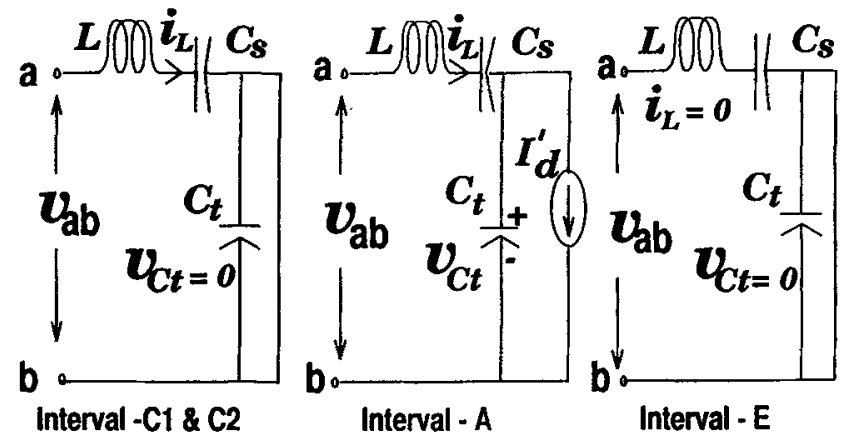

Figure 3. Equivalent circuit models for SPRC operating in DCM.

$L_{d}$ has to filter only HF ripple ( $2 f_{s}$, where $f_{s}$ is the switching frequency), whereas, $C_{d}$ has to filter the $120 \mathrm{~Hz}$ ripple.

The models required to analyse the converter during different intervals of operation (identified as interval-C1, A, C2, and E) for the waveforms of figure 2 are shown in figure 3. In view of low switching current ripple in $i_{d}(t)$ of the output section, constant current model has been used. Based on the above equivalent circuit models, the converter has been analysed using the state-space approach (it is complex due to four intervals of operation and three state variables) (Belaguli 1996). If active control is used to get sinusoidal line current, the variation in switching frequency over the $60 \mathrm{~Hz}$ ac half cycle for the given instantaneous $M(t)$ and $Q_{s}(t)$, have been evaluated using the converter gain equation. Figure 4 shows the plot of $Q_{s}(t), M(t)$, and $y_{s}(t)$ over the $60 \mathrm{~Hz}$ ac half cycle,

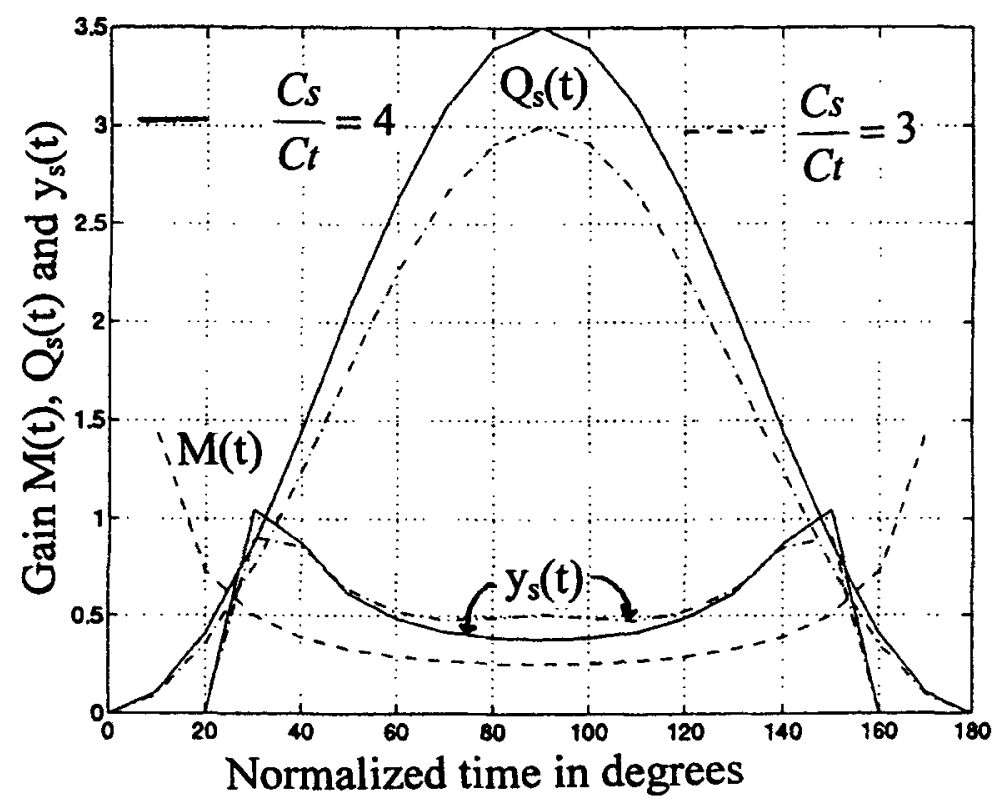

Figure 4. Variation of series $Q_{s}(t)$, required converter gain $M(t)$, and normalized switching frequency ratio $y_{s}$ to get sinusoidal line current over $a c$ half cycle for minimum $a c$ voltage and rated maximum load conditions. 
for two different values of $Q_{s \max }$ and $C_{s} / C_{t}$ ratio. However, if no active control is used, then it is necessary to properly choose the converter gain $M=V_{o}^{\prime} / V_{m}$ and $Q_{s \text { max }}$ at the peak of the $60 \mathrm{~Hz}$ sinusoidal $a c$ voltage cycle for a given $C_{s} / C_{t}$ ratio.

From the analysis, it was found that, for a given peak converter gain of $V_{o}^{\prime} / V_{m}=0.25$, good compromised design values are $Q_{s \max }=3$ and $Q_{s \max }=3.5$ for $C_{s} / C_{t}$ ratios of 3 and 4 respectively, with the converter operating in JCCM. But simulations showed that a capacitor ratio of 4 is preferable over 3 , due to lower harmonic distortion and lower inverter output peak currents.

3.4a Design example: A converter is to be designed with the following specifications.

Average output power, $P_{o}=150 \mathrm{~W}$;

Input voltage, $V_{a c}=120$ to $135 \mathrm{~V}$ rms;

Output voltage, $V_{o}=48 \mathrm{~V}$;

Full load current, $I_{o}=3.125 \mathrm{~A}$;

Output current ripple in $i_{d}, A_{i}= \pm 10 \%$ of $I_{o}$;

Output voltage ripple, $A_{v}= \pm 0.5 \%$ of $V_{o}$;

Series resonant frequency, $f_{s r}=135 \mathrm{kHz}$.

The design calculations are done for SPRC delivering a peak power of $2 P_{o}$ by choosing the $Q_{s}$ at the peak of the $a c$ line cycle (JCCM operation at this point) for rated minimum input voltage, i.e., $V_{a c}=120 \mathrm{~V}$.

Using $M=0.25, V_{m}=\sqrt{2} \times 120, V^{\prime} o=M V_{m}=42.5 \mathrm{~V}$.

$R_{L p}^{\prime}=V_{o}^{\prime 2} /\left(2 P_{o}\right)=6.02 \Omega, y_{s}=f_{s} / f_{s r}=0.4$, transformer turns ratio $n: 1=$ 0.8854 .

Using the definitions of $Q_{s}$ max and $y_{s}$, the following component values are obtained for $Q_{s \max }=3.5$ and $C_{s} / C_{t}=4$ :

$$
L=24.84 \mu \mathrm{H}, C_{s}=0.0559 \mu \mathrm{F}, C_{t}=0.0139 \mu \mathrm{F} .
$$

The output filter $L_{d}$ and $C_{d}$ are designed using the relationship given by Schutten $e t$ al (1991) and Belaguli (1996) to meet the output ripple requirements.

$$
L_{d}=V_{o} /\left(3 \pi f_{s} I_{o} A_{i}\right)=150 \mu \mathrm{H}, C_{d}=I_{o} /\left(180 \pi V_{o} A_{v}\right)=11,512 \mu \mathrm{F} .
$$

3.4b SPICE simulation results: The $150 \mathrm{~W}, 48 \mathrm{~V}$ output converter designed above has been simulated in SPICE to verify its performance. Due to storage limitations, SPICE simulation studies have been done for a converter redesigned with a switching frequency of $25 \mathrm{kHz}$, which does not change the operating principle and the actual results. Figure 5 shows the various waveforms obtained from SPICE simulation for the DCM operation of SPRC, for different load currents and $C_{s} / C_{t}=4$. The line current waveform for full load shown in figure 5a has a harmonic distortion of $14 \%$. The JCCM operation of the converter near the peak of $a c$ voltage waveform is shown in figure $5 \mathrm{~b}$. For $50 \%$ and $10 \%$ of the rated load, the line current waveforms are shown in figures $5 \mathrm{c}$ and $5 \mathrm{~d}$, which have distortion figures of $16 \%$ and $11 \%$ respectively, while the converter is operating only in the DCM mode. SPICE simulation studies showed that the line current THD for a capacitance ratio 3 was higher compared to 4 . The switching frequency harmonic component appearing in 


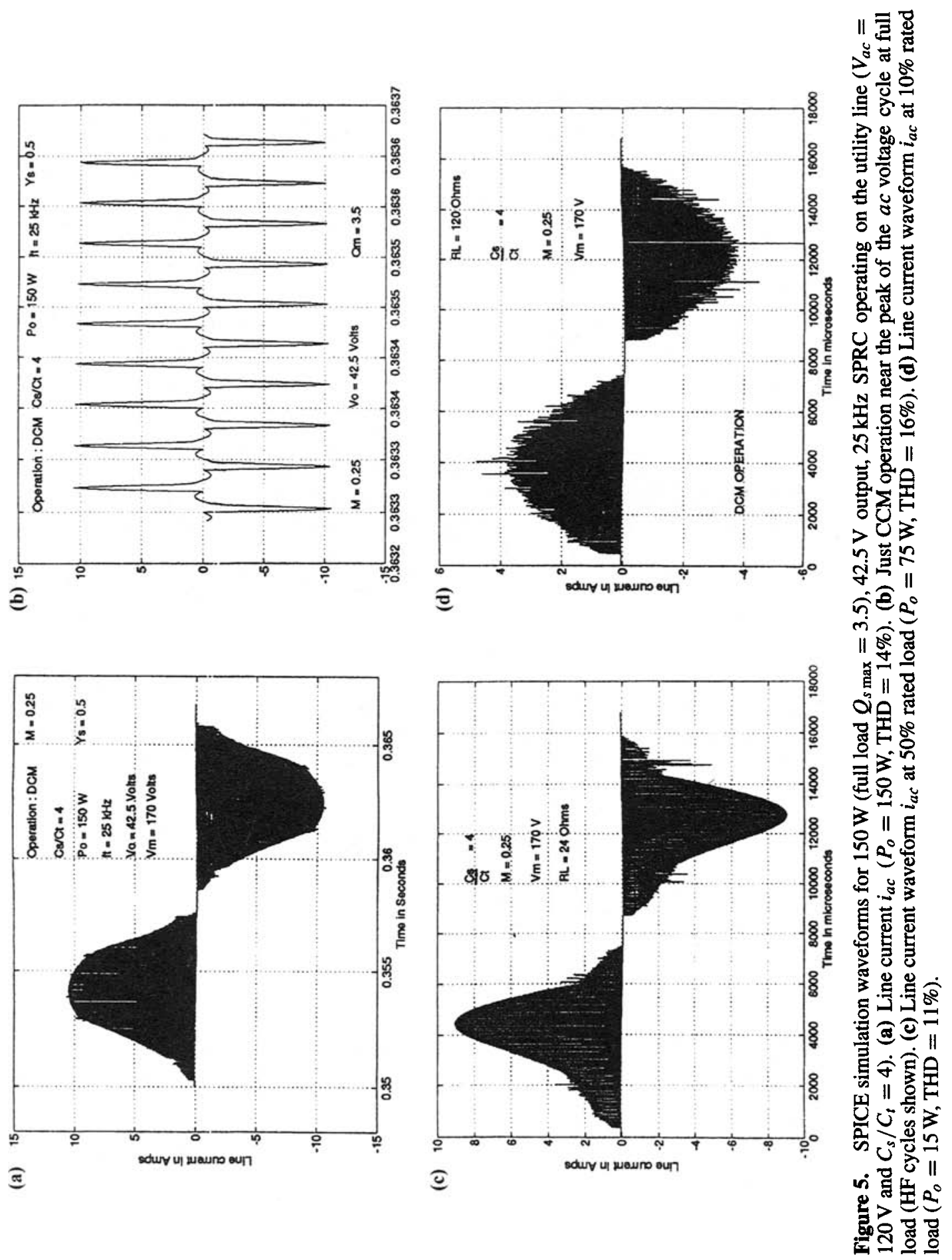


the line current waveforms shown in figure 5 are due to insufficient HF line filtering and they can be filtered using appropriate LC filters on the $a c$ side. It is also observed that with the choice of $C_{s} / C_{t}>4$, the converter characteristics approaches that of the SRC.

3.4c Experimental results: Based on the design presented in $\$ 3.4 \mathrm{a}$, an experimental prototype SPRC rated at $150 \mathrm{~W}, 42.5 \mathrm{~V}$ output, operating on $60 \mathrm{~Hz}, 120 \mathrm{~V}$ utility line was built using IRF740 MOSFET's in a bridge configuration and a 1:1 HF transformer. The SPRC converter was controlled using LD405 resonant controller. The filter components used were $L_{d}=150 \mu \mathrm{H}$ and $C_{d}=10,000 \mu \mathrm{F}$.

The various waveforms and line current harmonic spectra obtained from the prototype model are presented in figure 6 for different loading conditions with $C_{s} / C_{t}=4$. In these waveforms, for reduced loads, the frequency was decreased to get the desired regulated output voltage keeping the on time constant. Figure 6a(i) shows the line voltage, line current, output filter current and output voltage waveforms, while the corresponding line current harmonic spectra at full load (THD $=8.73 \%$ ) are shown in figure $6 \mathrm{a}$ (iii). The JCCM operation of the SPRC at full load near the peak of the $a c$ voltage cycle is shown in figure $6 \mathrm{a}(\mathrm{ii})$. For $50 \%$ rated load, line current waveform is shown in figure $6 \mathrm{~b}$. The THD increased to $12.9 \%$ at $50 \%$ load and then decreased to $8.9 \%$ at $10 \%$ rated load. The frequency was decreased from $68.96 \mathrm{kHz}$ (at full load) to $39.8 \mathrm{kHz}$ (at $10 \%$ load) in an open loop manner, to regulate the output voltage. The resonant peak current reduced from $10 \mathrm{~A}$ at full load to $4.5 \mathrm{~A}$ at $10 \%$ load. The line current waveform closely resembled sine wave with discontinuity near the valleys for entire load range. Near the valleys, discontinuity observed is due to insufficient voltage drive and converter gain to meet the required load demand and hence the distortion. All these waveforms and results closely conform with the SPICE simulations. The power factor is maintained close to unity, for the entire load range with DCM operation of the SPRC even without active control. However with active control, the line power factor can be further improved by waveshaping the line current waveform.

3.4d Advantages and disadvantages of DCM operation: Some of the desirable features or advantages of the described converter operating in DCM are as below.

(1) Single-stage $a c$-to- $d c$ power conversion without any active control with high power factor.

(2) Since the converter operates in DCM, ZCS is assured for all the switches with negligible switching losses. Output diodes operate with ZVS. This allows very high switching frequency.

(3) The capacitor $C_{t}$ is placed on the secondary-side of the HF transformer to take advantage of the leakage inductance as part of resonant inductance.

(4) The value of resonant inductance required is very small. The value of resonant capacitors are also small.

(5) The output filter inductance $\left(L_{d}\right)$ is small since it has to filter twice the switching frequency. 
(a)(i)

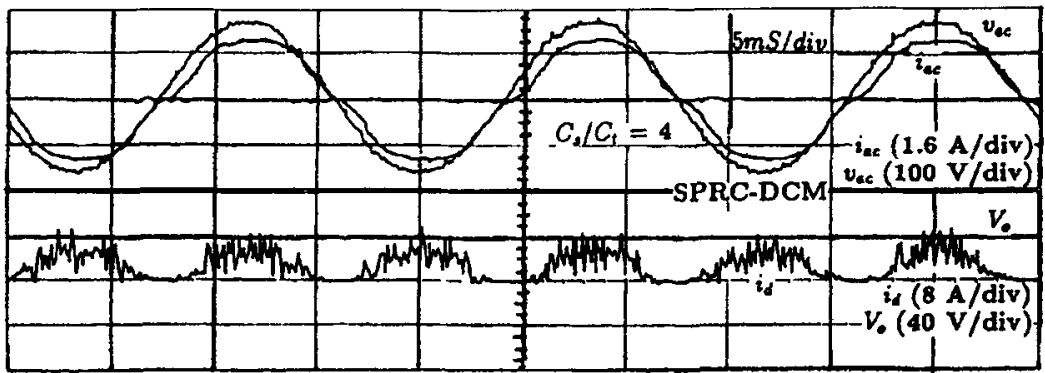

(a)(ii)

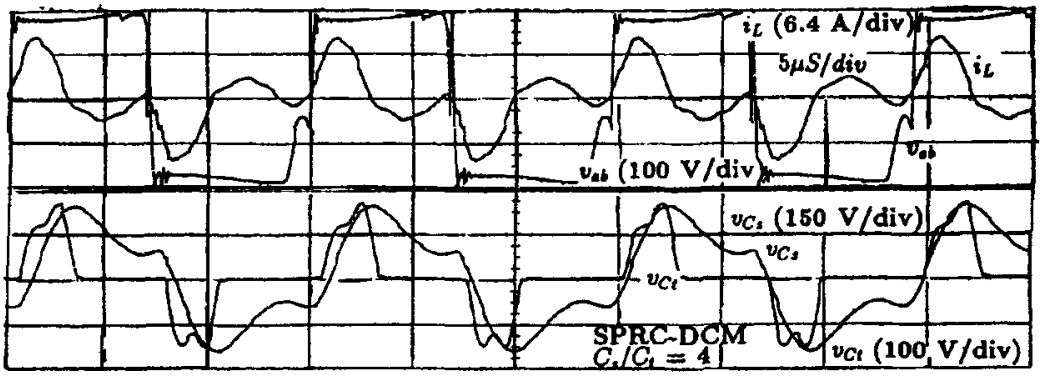

(a)(iii)

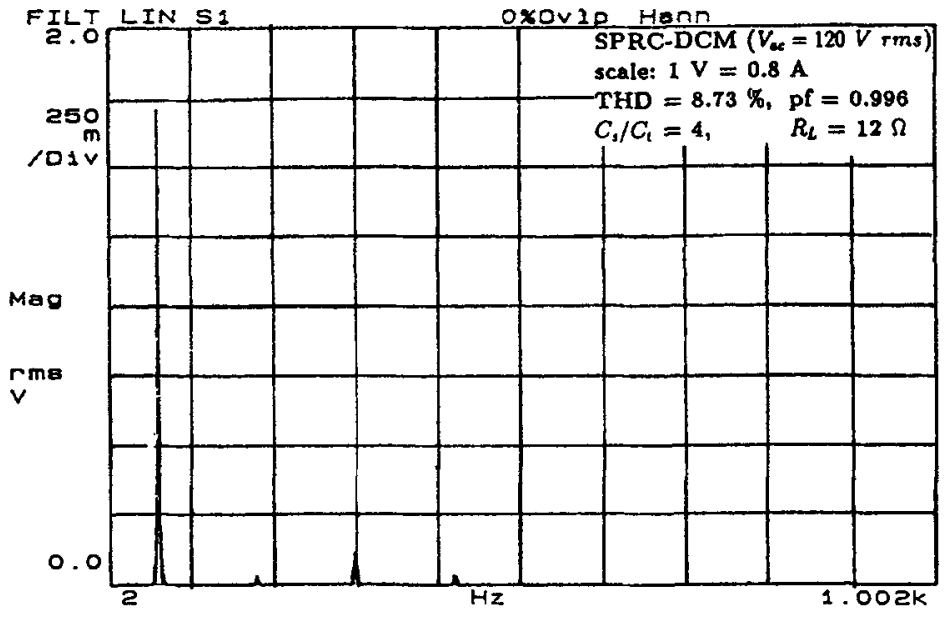

(b)

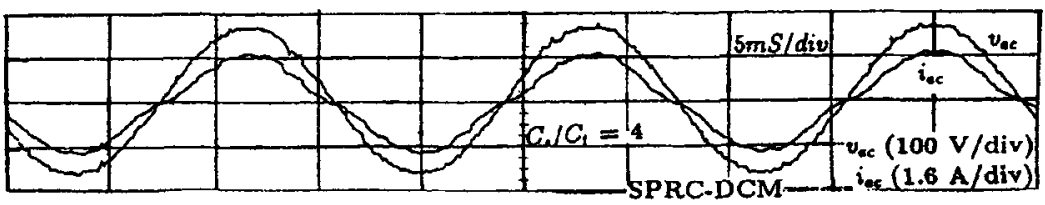

Figure 6. Experimental waveforms for the DCM converter designed in § 3.3a. (a) At full load $\left(R_{L}=12 \Omega, P_{o}=150 \mathrm{~W}\right)$ : (i) input voltage $v_{a c}$, line current $i_{a c}$, filter current $i_{d}$, output voltage $V_{a}$, (ii) $v_{a b}$ and $i_{L}, v_{C t}$ and $v_{C s}$ near the peak of utility $a c$ voltage, (iii) line current harmonic spectra for $i_{a c}$. (b) Half load $\left(R_{L}=24 \Omega, P_{o}=75 \mathrm{~W}\right): v_{a c}$ and $i_{a c}$. 
(6) In the experimental converter, MOSFETs were used as the switching devices requiring a series by-pass diode and another anti-parallel diode. IGBTs are better suited for ZCS application, also use of IGBTs is expected to reduce the conduction losses. Due to the availability of IGBTs with fast internal diodes, series diodes are not required. Mos-Controlled-Thyristors (MCTs) can also be used in the converter presented.

Some of the problems with the proposed converter are the following.

(1) Switch peak currents are quite high. Therefore IGBTs are the better switching devices, but there is a limitation on the highest switching frequency. The rectifier diode voltage ratings are high due to peak voltage across $C_{t}$.

(2) Since variable frequency operation is used for power control, lowest frequency sets the limit on the size of the HF transformer.

(3) Lossy snubbers are required.

(4) Output filter capacitor $C_{d}$ has to filter the $120 \mathrm{~Hz}$ ripple and, therefore, is large especially for lower output voltages limiting the transient response of the converter. This problem exists in all single stage $a c$-to- $d c$ converters with low harmonic distortion.

\subsection{Continuous current mode of operation}

The SPRC can operate in leading $p f$ (below resonance) or lagging $p f$ (above resonance) modes depending on the switching frequency (or pulse-width when fixed-frequency control is used), resonant component values and the load. It has been shown that operation in lagging pf (ZVS) mode has several advantages (use of lossless snubbers, no turn-on losses, use of internal diodes of MOSFETs etc.) compared to leading $p f$ mode of operation.

Using ac complex circuit approximate analysis, it can be shown (Steigerwald 1988; Bhat 1991) that the converter gain for a $d c$-to- $d c$ SPRC is given by

$$
\begin{aligned}
M=V_{o}^{\prime} / V_{m, \min }=\sin (\delta / 2) & /\left[\left(\pi^{2} / 8\right)\left(1+\left(C_{t} / C_{s}\right)\left(1-y_{s}^{2}\right)\right\}^{2}\right. \\
+ & \left.\left(Q_{s}\left\{y_{s}-\left(1 / y_{s}\right)\right\}\right)^{2}\right]^{1 / 2} \text { per unit }
\end{aligned}
$$

where, $Q_{s}=\left(L / C_{s}\right)^{1 / 2} / R_{L}^{\prime}$ and $\delta=\pi$ for variable frequency control.

Figures $7 \mathrm{a}$ and $\mathrm{b}$ show the plots of the converter gain $M$ as a function of the normalized switching frequency $y_{s}$, for capacitance ratios of 0.5 and 1 , respectively, when the converter operates as a $d c$-to- $d c$ converter with constant $d c$ input. When operated as an $a c$-to- $d c$ converter as explained earlier with an $\mathrm{HF}$ capacitor $C_{i}$, the required variation in converter gain $M(t)$, switching frequency ratio $y_{s}(t)$ and $Q_{s}(t)$ over the $60 \mathrm{~Hz}$ cycle to draw nearly sinusoidal line current from the utility line when active control is used are plotted in figure 8 . The sharp dip in $y_{s}$ curve in figure 8 is due to insufficient gain near the zero crossings at chosen operating point. However, if no active control is used, the operating point has to be chosen carefully to satisfy all the design constraints mentioned in $\S 3.3$. For variable frequency CCM operation, choosing $y_{s}$ closer to the load-independent point on the gain curve reduces the range of variation in frequency required from full load to light load, in addition to reduction of inverter peak current stresses. Good compromised design values are: $Q_{s \max }=3.2, M=V_{o}^{\prime} / V_{m, \min }=1, y_{s}=1.153$ for $C_{s} / C_{t}=0.5$. Similarly for 


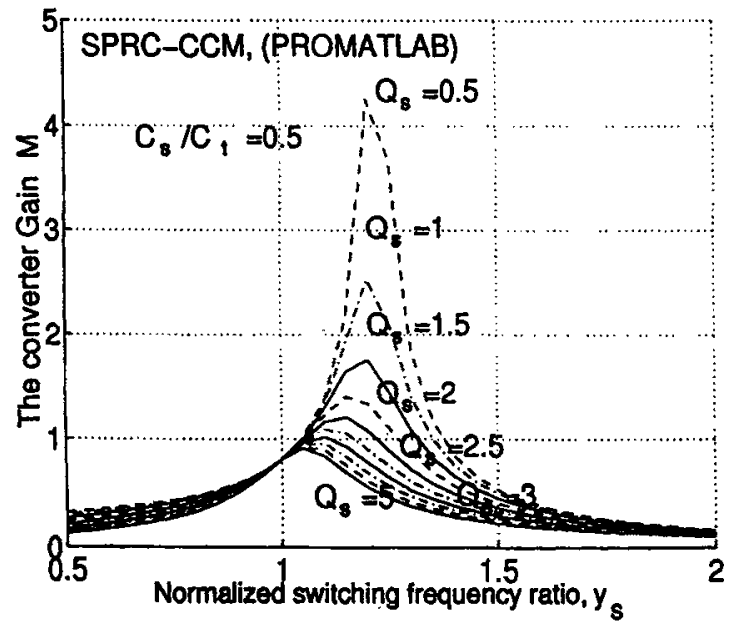

(a)

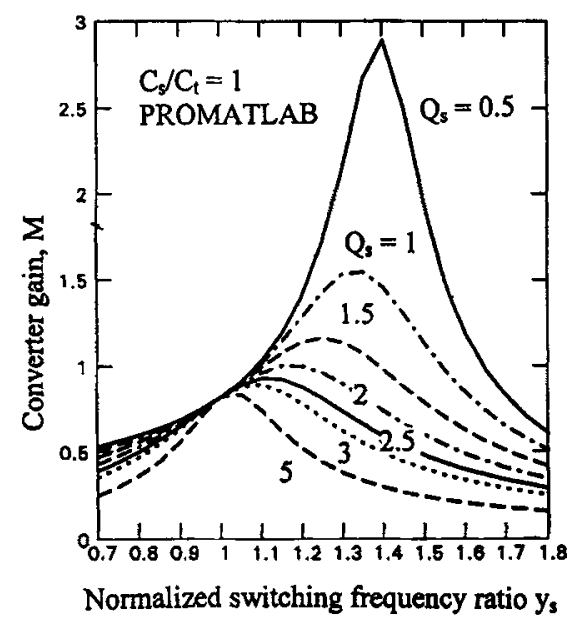

(b)

Figure 7. DC Voltage gain, $M$ for CCM operation of the SPRC. (a) $C_{s} / C_{t}=0.5$, (b) $C_{s} / C_{t}=1$.

$C_{s} / C_{t}=1$, the design values are $M=0.75, y_{s}=1.195$. The above design values for the converter will ensure lagging $p f$ mode (or ZVS) operation, in addition to generating the required voltage gain near the valleys of the $a c$ voltage, while delivering rated output power at rated minimum input voltage.

3.5a Design example: A converter is to be designed with the following specifications.

Average output power, $P_{o}=150 \mathrm{~W}$,

Input voltage, $V_{a c}=85$ to $110 \mathrm{~V}$ rms,

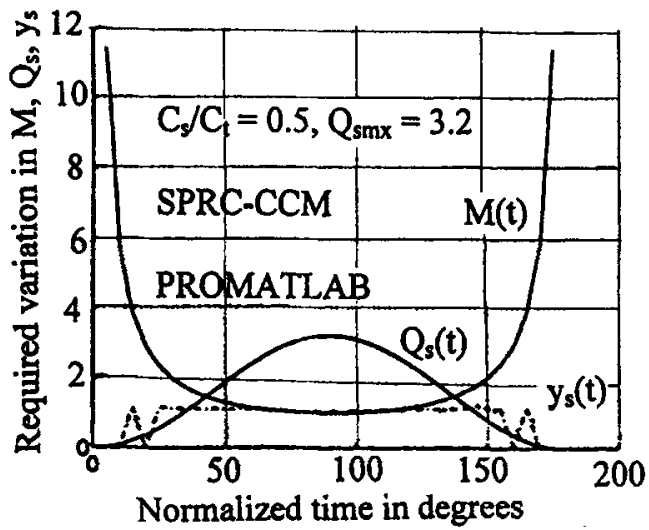

(a)

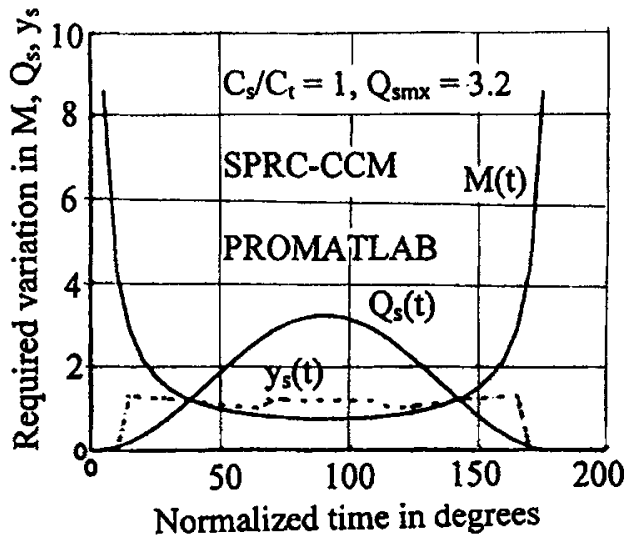

(b)

Figure 8. Variation of series $Q_{s}(t)$, required converter gain $M(t)$, and normalized switching frequency ratio $y_{s}(t)$ to get sinusoidal line current over $a c$ half cycle for minimum $a c$ input voltage and rated maximum load conditions for SPRC operating in CCM. (a) $C_{s} / C_{t}=0.5$, (b) $C_{s} / C_{t}=1$. 
Output voltage, $V_{o}=120 \mathrm{~V}$

Output current ripple, $A_{i}= \pm 20 \%$ of $I_{o}$,

Output voltage ripple, $A_{v}= \pm 0.2 \%$ of $V_{o}$,

Switching frequency, $f_{s}=50 \mathrm{kHz}$.

The design calculations are done for SPRC delivering a peak power of $2 P_{o}$ by choosing the $Q_{s}$ at the peak of minimum rated line voltage. Using the relations for $Q_{s} \max$ and $y_{s}$, the component values obtained are given below for the two cases.

Case 1: $C_{s} / C_{t}=0.5, Q_{s \max }=3.2, y_{s}=1.153, M=1$,

$$
\begin{aligned}
& V^{\prime} o=M V_{m}=120 \mathrm{~V}, n: 1=1: 1, R_{L}^{\prime}=96 \Omega, L=563.7 \mu \mathrm{H}, \\
& C_{s}=0.0238 \mu \mathrm{F}, C_{t}=0.0478 \mu \mathrm{F} .
\end{aligned}
$$

Case 2: $C_{s} / C_{t}=1, Q_{s \max }=3.2, y_{s}=1.195, M=0.75$,

$$
\begin{aligned}
& V_{o}^{\prime}=M V_{m}=90 \mathrm{~V}, n: 1=0.75: 1, R_{L}^{\prime}=54 \Omega, L=328.65 \mu \mathrm{H}, \\
& C_{s}=0.044 \mu \mathrm{F}, C_{t}=0.044 \mu \mathrm{F} .
\end{aligned}
$$

3.5b SPICE simulation results: The $150 \mathrm{~W}, 120 \mathrm{~V}$ output, $50 \mathrm{kHz}$ converter designed in $\$ 3.5$ a (case 1) was simulated in SPICE3 to evaluate the converter performance without active current control. For $C_{s} / C_{t}=0.5$, the harmonic distortion in the line current waveform (figure $9 \mathrm{a}(\mathrm{i})$ ) is $14.11 \%$ at full load and rated minimum input voltage. The SPRC operates in lagging $p f$ mode near the peak, and leading $p f$ mode near the zero crossings of the $a c$ voltage cycle. The line current waveform for $53 \%$ load, shown figure $9 \mathrm{a}$ (ii) has a THD of $15.5 \%$. The SPRC operated fully in lagging $p f$ mode for decreased load currents due to increase in $y_{s}$ for regulated output.

Similarly for a capacitance ratio of 1 and at full load, the line current THD was $19.8 \%$ (figure 9b), and the converter operated in discontinuous capacitor voltage mode (DCVM), while delivering rated output power at rated minimum input ac voltage. Since the converter operated in DCVM at full load and in CCVM at reduced load, the range of variation in switching frequency to regulate the output was larger for $C_{s} / C_{t}=1$. In all these simulations the switching frequency $f_{s}$ was increased to regulate the output voltage at reduced loads.

3.5c Experimental results: Based on the design presented in $\$ 3.5 \mathrm{a}$, a breadboard model of SPRC rated at $150 \mathrm{~W}$, operating on $60 \mathrm{~Hz}, 85 \mathrm{~V}$ to $110 \mathrm{~V}$ utility line was built using IRF640 MOSFET's in a bridge configuration and a readily available $1: 1 \mathrm{HF}$ transformer having 12 turns each. The SPRC was controlled using UC2825 PWM controller, configured for variable frequency operation.

(1) Without active control - The various waveforms obtained from the prototype model are presented in figure 10 for different loading conditions and $C_{s} / C_{t}=0.5$. The THD obtained for the line current waveform (full load, rated minimum input voltage) presented in figure $10 \mathrm{a}(\mathrm{i})$ is $13.5 \%$. The lagging $p f$ and leading $p f$ operation along with the resonant capacitor voltage waveforms at full load, near the peak and the valleys of the ac voltage 


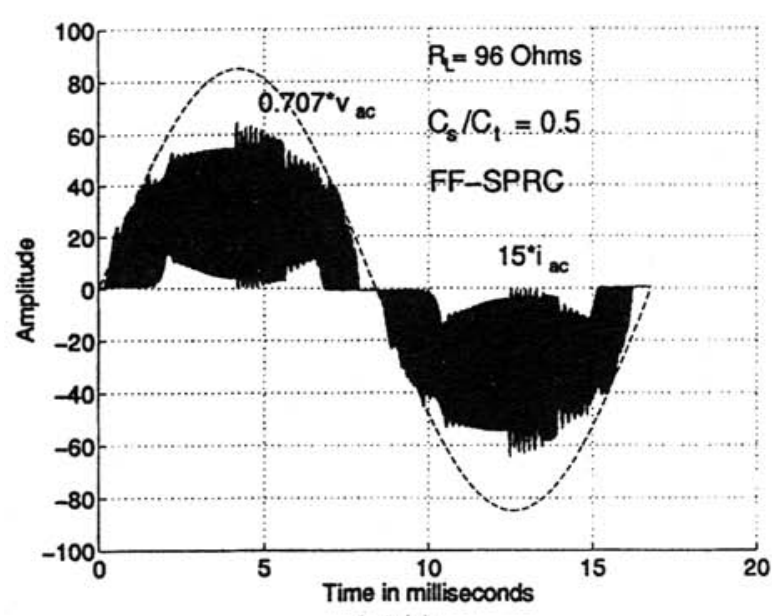

(a)(i)

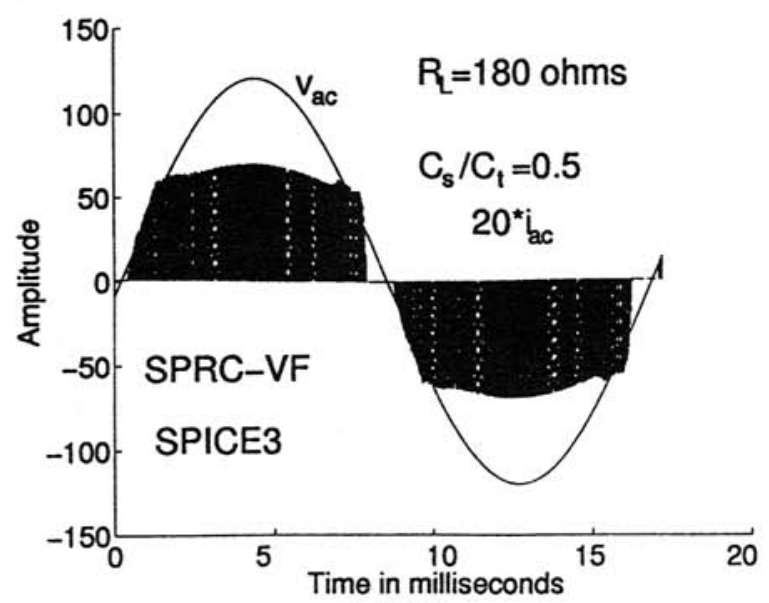

(a)(ii)

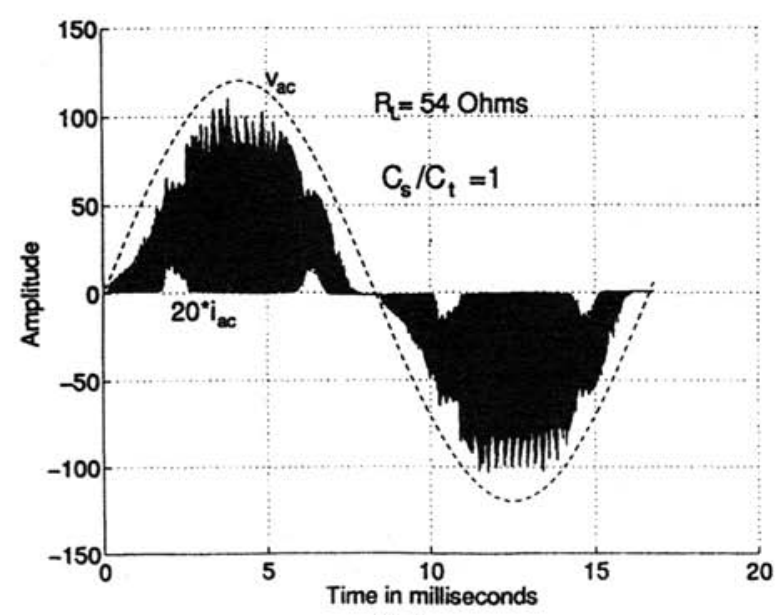

(b)
Figure 9. SPICE3 simulation waveforms for $150 \mathrm{~W}$ (full load), $120 \mathrm{~V}$ output, $50 \mathrm{kHz}$ variable frequency SPRC operating on the utility line in CCM without active control $\left(V_{a c}=85 \mathrm{~V}\right)$. Waveforms $v_{a c}$ and $i_{a c}$ for (a) $C_{s} / C_{t}=0.5$ : (i) at full load and (ii) at $53 \%$ load; (b) $C_{s} / C_{t}=1$ : at full load. 


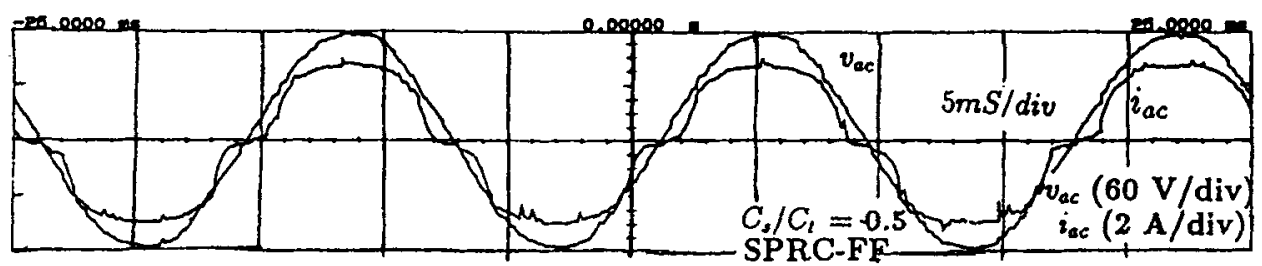

(a)(i)

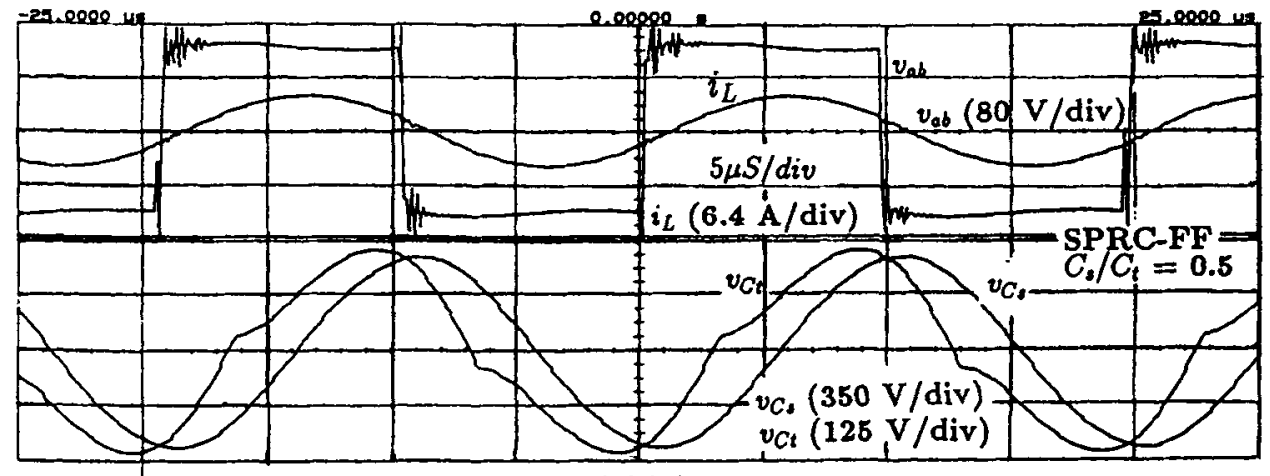

(a)(ii)

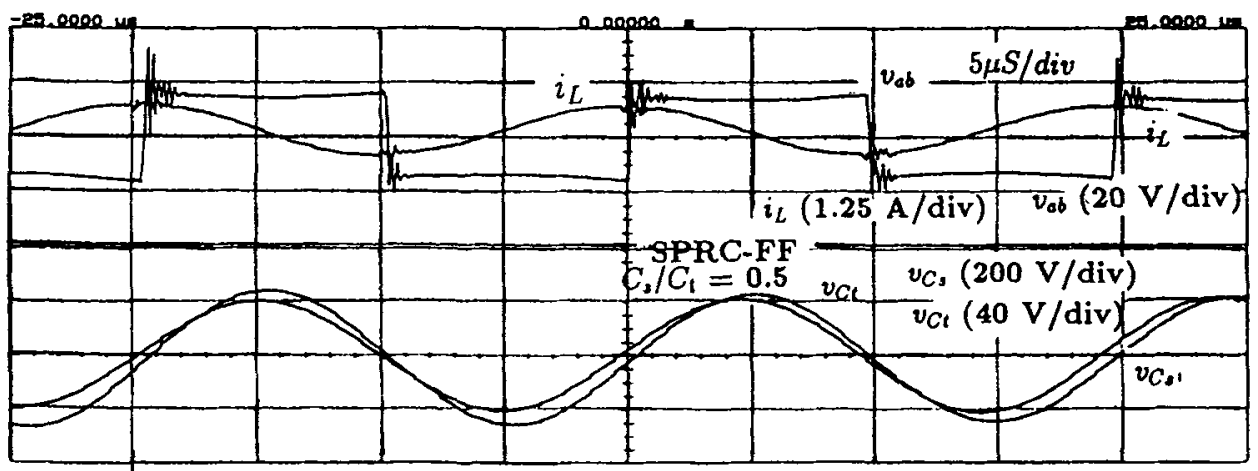

(a)(iii)

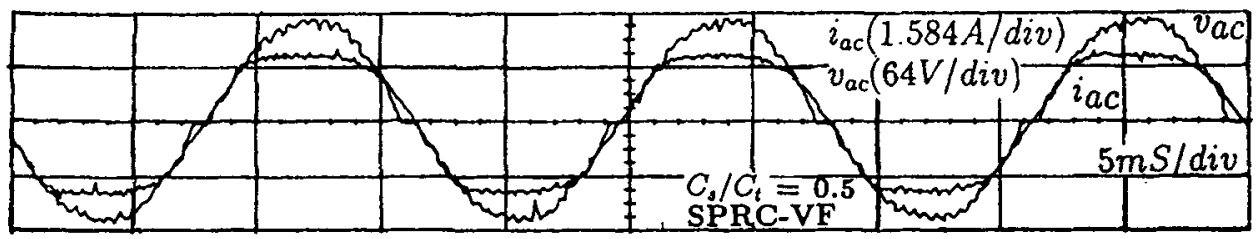

(b)

Figure 10. Experimental waveforms for different load conditions for a $120 \mathrm{~V}$ output, variable frequency SPRC operating on the utility line without active control $\left(C_{s} / C_{t}=0.5, L_{d}=\right.$ $500 \mu \mathrm{H}, C_{d}=1000 \mu \mathrm{F}, V_{a c}=85 \mathrm{~V} \mathrm{rms}$; (a) full $\operatorname{load}\left(R_{L}=96 \Omega\right.$ ): (i) $v_{a c}$ and $i_{a c}$, (ii) $v_{a b}$ and $i_{L}, v_{C t}$ and $v_{C s}$ near the peak of $a c$ voltage and (iii) $v_{a b}$ and $i_{L}, v_{C t}$ and $v_{C s}$ near the valleys of ac voltage. (b) $53 \% \operatorname{load}\left(R_{L}=180 \Omega\right): v_{a c}$ and $i_{a c}$. 


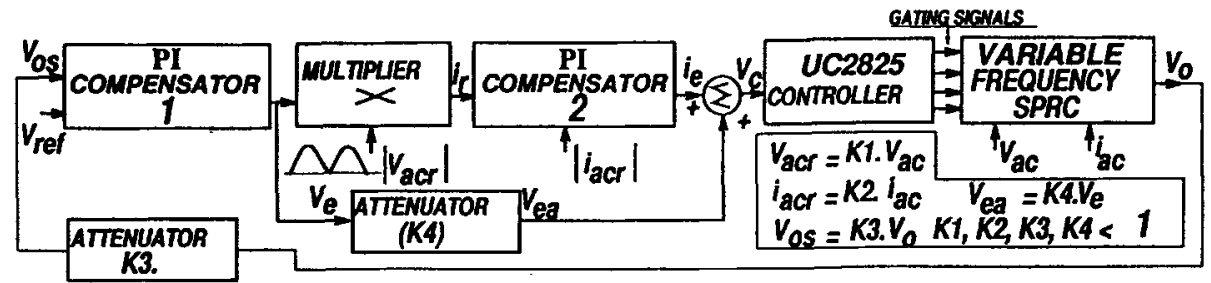

Figure 11. Active current control scheme block diagram for SPRC bridge (figure 1) operating on the utility line.

cycle are shown in figures $10 \mathrm{a}$ (ii) and (iii), respectively. At full load the predominant harmonic components are 5th and 7th. The THD reached a minimum of $11.9 \%$ at $53 \%$ load for the line current shown in figure 10(b). The maximum distortion occurred at an operating frequency of $54.5 \mathrm{kHz}$, at $80 \%$ load, due to over-boosting effect at all points along the ac cycle. The peak current reduced from $5.4 \mathrm{~A}$ at full load to $3.75 \mathrm{~A}$ at $10 \%$ load.

For an input voltage of $110 \mathrm{~V} \mathrm{rms,} \mathrm{the} \mathrm{THD} \mathrm{reached} \mathrm{a} \mathrm{maximum} \mathrm{(due} \mathrm{to} \mathrm{square} \mathrm{wave-}$ form) and minimum of $34.5 \%$ and $12.8 \%$, at full load and $53 \%$ load, respectively. For regulated output, the required variation (increase) in switching frequency for the complete load and line variation is $50 \mathrm{kHz}$ to $63.93 \mathrm{kHz}$. Experimental results also confirmed the simulation results for $C_{s} / C_{t}=1$.

(2) With active current control - In order to reduce the line current THD, variable frequency active current control scheme has been implemented, and the details are given below. The block schematic of the active current control scheme implemented with the breadboard model is shown in figure 11. In order to keep the output voltage constant for varying input voltage and output load, and also to keep the input line current close to sinusoidal and in phase with the line voltage, the proposed control scheme is equipped with two control loops, namely:

(a) The outer voltage feedback loop: This is a slow varying loop consisting of an output voltage sensing amplifier, PI compensator- 1 and a multiplier. The output voltage is sensed by a voltage divider $\left(V_{o s}\right)$ and compared with set reference signal $\left(V_{r e f}\right)$ using a PI compensator. The error signal $V_{e}$ in combination with sinusoidal reference $\left|V_{a c r}\right|$ is used to generate the varying amplitude sinusoidal reference current $i_{r}$ for referencing the inner current control loop.

(b) The inner current control loop: The current controlling feedback loop is used to monitor the mains current $i_{a c}$ and force it to follow the mains voltage. This control loop consists of a PI compensator-2, with inputs as, conditioned line current waveform $\left|i_{a c r}\right|$ to be shaped and the reference current $i_{r}$. The reference current signal $i_{r}$ has quick control of the line current while the output voltage error $V_{e}$ has a slow control over the line current. The result is that the $d c$ link current varies as a rectified sinusoid and the voltage regulation is achieved by adjusting the amplitude of the voltage error signal $V_{e}$. Finally the control voltage $V_{c}$ to the UC2825 controller is generated by summation of error $i_{e}$ and $V_{e a}$ after proper scaling and limiting circuits.

Some sample experimental waveforms obtained from variable frequency active control scheme are presented in figure 12 , corresponding to a capacitance ratio of 1 . For rated minimum input voltage, the line current waveforms presented in figures $12 a(i)$ and $b$ have 
(a)(i)

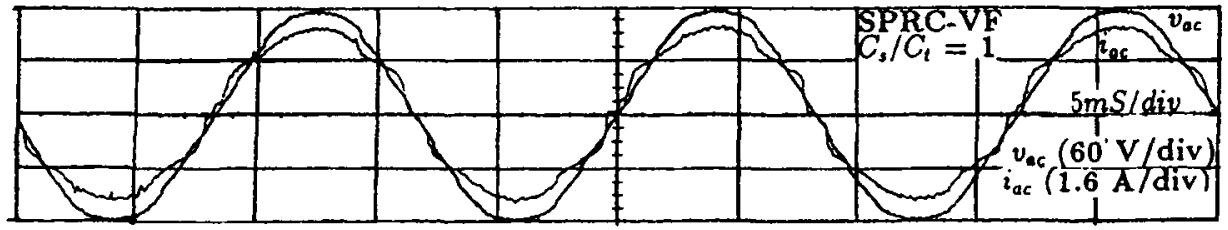

(a)(ii)

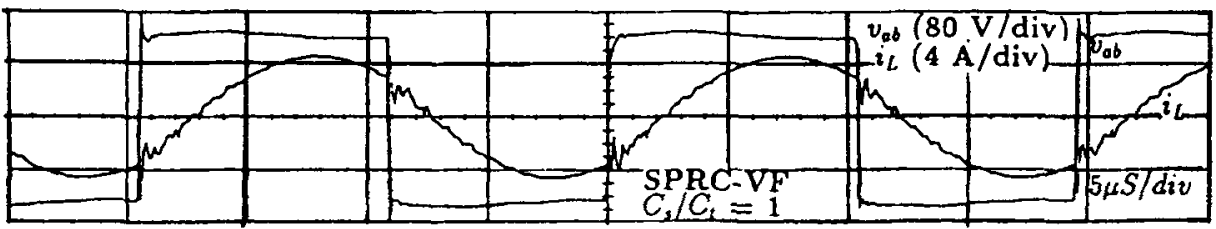

(a)(iii)

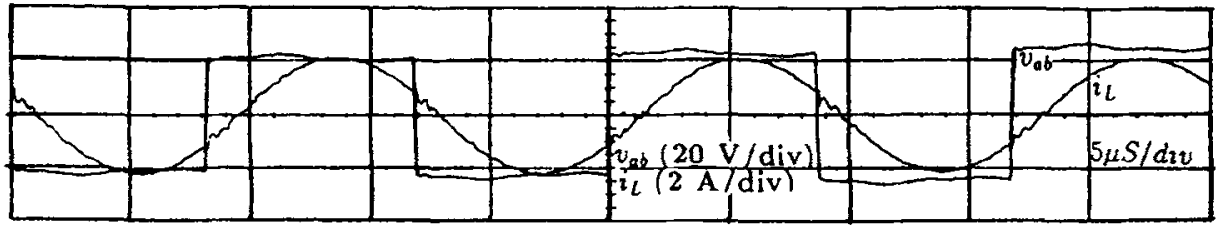

(b)

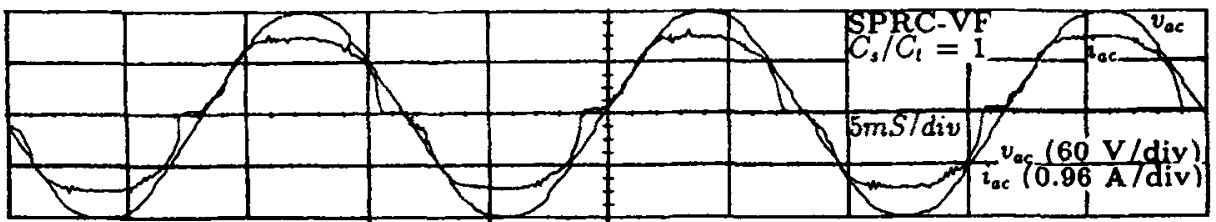

Figure 12. Experimental waveforms for a $90 \mathrm{~V}$ output variable frequency SPRC operating on the utility line with active current control $\left(C_{s} / C_{t}=1, L_{d}=500 \mu \mathrm{H}, C_{d}=1000 \mu \mathrm{F}\right.$, $\left.V_{a c}=85 \mathrm{~V} \mathrm{rms}\right)$. (a) At full load $\left(R_{L}=54 \Omega\right)$ : (i) $v_{a c}$ and $i_{a c}$, (ii) $v_{a b}$ and $i_{L}$ near the peak of $a c$ voltage and (iii) $v_{a b}$ and $i_{L}$ near the valleys of $a c$ voltage. (b) $50 \%$ load $\left(R_{L}=108 \Omega\right)$ : $v_{a c}$ and $i_{a c}$.

distortion figures of $7.4 \%$ and $11.33 \%$, at full load and $50 \%$ load respectively. As shown in figures a(ii) and (iii) for full load, the operating frequency near the peak and valleys of $a c$ voltage are $51.28 \mathrm{kHz}$ and $58.82 \mathrm{kHz}$, respectively. The converter operated with ZVS operation for all the switches throughout the $a c$ cycle with active control at full load.

\subsection{Fixed-frequency SPRC}

In this case, the SPRC is designed for operation with $\delta=\pi$ (equation 4) at full load with minimum rated supply voltage. Therefore, the design is the same as the variable frequency CCM case. Power control is achieved by phase shifting the gating signals to obtain a quasi-square-wave $v_{A B}$ with pulse-width $d$. Based on the design example presented in $\S 3.5 \mathrm{a}$, the converter was simulated using SPICE (Belaguli \& Bhat 1995) for variable load and line voltage. It was observed that a narrow variation in pulse-width is required for regulating the output from full load to light load. It was also verified experimentally that the THD of line current is reduced by active current control scheme with pulse-width being 
changed throughout the line cycle. The major problem with fixed-frequency control is that the converter operates in leading $p f$ mode for most part of the cycle.

\section{Conclusions}

Operation of resonant converters on the utility line with high $p f$ and low harmonic distortion has been presented. Design examples have been presented for the variable frequency controlled SPRC operating in DCM and CCM. The SPICE3 simulation and experimental results show that, by proper converter design, one can get low line current THD and high $p f(>0.97)$ with SPRC even without active control. The capacitance ratio 0.5 is preferred as the THD figures, the peak current stresses and range of variation in frequency from full load to light load are lower as compared to those figures obtained for $C_{s} / C_{t}$ ratio 1 , when no active control is used. With the implementation of active control scheme, the $p f$ is maintained close to unity ( $>0.99$ ) with further reduction in THD. For active current control, capacitance ratio 1 is recommended as the THD figures are lower (8\% at full load). Slightly higher current stresses obtained for $C_{s} / C_{t}$ ratio 1 are due to DCVM operation and as a consequence require larger variation in frequency to regulate the output voltage. The experimental converter built had a switching frequency of $50 \mathrm{kHz}$ at full load and this was used only to demonstrate the high $p f$, low THD that can be obtained with variable frequency operation of SPRC. However higher switching frequency can be used with active control scheme, as ZVS operation is maintained over the entire $60 \mathrm{~Hz}$ ac cycle.

\section{References}

Belaguli V 1996 Series-parallel and parallel-series resonant converters operating on the utility line - analysis, design, simulation and experimental results. $\mathrm{Ph} \mathrm{D}$ dissertation, Department of Electrical and Computer Engineering, University of Victoria, Canada

Belaguli V, Bhat A K S 1995 Characteristics of fixed frequency series-parallel resonant converter operating on the utility line with and without active control. IEEE Power Electronics and Drive Systems (PEDS '95) Conference Record, pp 168-173

Bhat A K S 1991 A unified approach for the steady-state analysis of resonant converters. IEEE Trans. on Ind. Electron. 38: 251-259

Chambers D 1983 A new high frequency resonant technique for dynamic correction of off-line converter input current waveforms. Proceedings of Powercon 10, paper \# F-1, pp 1-7

$\mathrm{He} \mathrm{J}$, Mohan N 1987 Input-current shaping in line-rectification by resonant converters. IEEE Industry Applications Society Conference Records, pp 990-995

Kataoka T, Mizumachi K, Miyairi T 1979 A pulse-width controlled AC to DC converter to improve power factor and waveform of AC line current. IEEE Trans. Ind. Appl. 15: 670-675

Keraluwala M H, Steigerwald R L, Gurumoorthy R 1991 A fast-response high power factor converter with a single power stage. IEEE Power Electronics Specialists Conference Record, pp 769-779

Kocher M J, Steigerwald R L 1983 An $a c$ to $d c$ converter with high quality input waveforms. IEEE Trans. Ind. Appl. 19: 586-599

Nijhof E B G 1986 Resonant power supply (RPS) converters: The solution for mains/line pollution problems. Proc. Power Conversion Int. Conf. Rec. pp 104-139 
Schlecht M F, Miwa B A 1987 Active power factor correction for switching power supplies. IEEE Trans. Power Electron. PE-2: 273-281

Schutten M J, Steigerwald R L, Keraluwala M H 1991 Characteristics of load resonant converters in a high power factor mode. IEEE Applied Power Electronics Conference Record, pp 5-16

Steigerwald R L 1988 A comparison of half-bridge resonant converter topologies. IEEE Trans. Power Electron. 3: 174-182 